\title{
Competition in Media Systems and Voter Knowledge: An Agent-Based Model
}

\author{
Martijn Schoonvelde \\ Vrije Universiteit \\ mschoonvelde@gmail.com
}

February 8, 2018

\begin{abstract}
This paper presents an agent-based model (ABM) that shows that variation in voter knowledge can in part be driven by competition among media outlets. Using a set of simple behavioral rules implemented by voters, parties and media outlets, the model predicts that stronger media competition increases political knowledge of quality-minded voters vis-à-vis motivated reasoners although aggregate differences are small. This is because these voters are most likely to consume news even when it is of low quality. Not only do these results contribute to a larger (empirical) debate about media competition and political knowledge, but the model also serves as a theoretical starting point for exploring these patterns further.
\end{abstract}

Keywords: political knowledge, party competition, incomplete information, media reporting, agent-based modeling 


\section{Introduction}

Political knowledge is not just a function of a citizen's characteristics like education and political interest but also depends on the political information present in the media environment (Jerit, Barabas and Bolsen 2006). But what explains content of political media coverage? To answer this question we need to know what drives reporting of media outlets. Yet research in political science has not systematically studied this issue. Oftentimes, media reports are taken as an exogenous starting point for study, treating mass media as "a conveyor belt that passively transports elite views [...] to the public" (Baum and Potter 2008: p.40). But media outlets can also be thought of as producers of political news that respond to market incentives (Gentzkow and Shapiro 2008a; Hopkins, Kim and Kim 2017). Gentzkow and Shapiro (2008a: p.108) note: "For free markets to provide accurate information requires three things: that consumers want to hear the truth, that markets provide incentives to give consumers what they want, and that firms respond to these incentives. None of these is a given." Thus, media outlets may enhance political knowledge if enough of the public wants good information (see also Snyder Jr and Strömberg 2010).

The model presented here is concerned mass media coverage and political knowledge. It evaluates whether competition among media outlets can explain differences in political knowledge among the public. Following a set of behavioral rules implemented by voters, parties and media outlets, the model shows that stronger media competition increases political knowledge of quality-minded voters vis-à-vis motivated reasoners although aggregate differences are small. This is because these voters are more likely to consume news even if it is of low quality. These results not only contribute to a larger (empirical) debate about media competition and political knowledge, but can also serve as a theoretical starting point for exploring these patterns further

This paper proceeds as follows. In the next section I will briefly discuss ABMs in political science and situate this work among them. After that, I present the model and discuss the results. I then conclude. 


\section{ABMs of Political Competition}

ABMs of political competition have risen in popularity among political scientists, following a seminal paper by Kollman, Miller and Page (1992), who develop a theory of party competition "as a complex and evolving system where key actors hold very incomplete and imperfect information" (Laver 2005). Kollman, Miller and Page find that parties employing various search algorithms systematically converge to the location of the median voter. This occurs regardless of the exact spatial distribution of voter preferences, although more "rugged" or "less smooth" preferences slow down the process of convergence (Kollman, Miller and Page 1998). An important extension comes from De Marchi (1999) who lets go of the assumption of perfect information, but rather considers voters as "information misers" who try to minimize costly attention paid to politics. More specifically, they increase (decrease) attention to politics in case they are unsatisfied (satisfied) with the last election outcome. De Marchi finds that cycles in voter attention and party victory may occur, which are mainly driven by how much parties are vote-seeking and the 'intelligence' of voters. Laver (2005) has extended these models by considering a setting of multiparty competition in a two-dimensional space, as well as valence issues, party birth, party death, and evolution of party strategies (Laver and Sergenti 2011; Laver and Schilperoord 2007). In all these extensions, voters hold perfect information about the policy positions of all parties.

Thus, these ABMs exogenously vary the level of information (complete versus incomplete). Yet from the perspective of the "knowledge-as-choice" approach, political knowledge results from goal-oriented decision-making by individual citizens (Gordon and Segura 1997; Schoonvelde 2014). Since individuals obtain much of their political information from mass media outlets, this implies that another way to model voter knowledge is as endogenous to the presence of (market-based) media outlets. Strömbäck (2008: p. 234) notes: "What is thus required is a conceptualization of media influence that is sensitive to and recognizes the interactions and interdependencies of media systems, institutions and actors, political systems, culture, and sense making." The current model contributes to that goal. 


\section{The Model}

The model presented here has actors follow predetermined ('trial-and-error') behavioral rules. ${ }^{1}$ Implicit in this approach is that all actors have limited information about the state of the world which they use to inform their decision-making. Such behavioral decision rules are generally referred to as Aspiration-Based Adaption Rules (ABARs), in which agents compare payoffs to an aspiration level or reference point, and increase (decrease) the likelihood of behavior that results in payoffs that exceed (fall short of) that reference point (Bendor, Diermeier and Ting 2003).

The following empirical observations inform the model. First, many voters rely for their (political) information on traditional mass media outlets. ${ }^{2}$ Second, the quality of political content varies across these outlets, which in turn affects what readers learn. A typical write-up from the presidential campaign trail in the New York Times will contain more information than a similar article in the New York Post. Third, this variation in quality is not exogenous as media outlets respond to reader demand (Gentzkow and Shapiro 2008b).

In the model, there are $P=2$ parties competing in elections with $V$ sincere voters and $N$ media outlets in $T$ rounds. Each period $t$ denotes an election cycle consisting of a campaign plus an election. Table 1 displays the timing of the model. Steps 1 through 9 represent one time (campaign) period. In what follows, I specify the decision rules for parties, voters and media outlets.

Table 1: One Time Period in the Model

\footnotetext{
1) Incumbent and challenger party campaign for office.

2) Exogenous policy shock, $y_{t} \sim T N\left(I_{p, i n c}, 1,0,1\right)$.

3) Media outlets report on party platforms with quality $c_{n, t}$.

4) Voters decide to buy news reports with probability $q_{v, t}$.

5) Voters update beliefs about party platforms using Bayes rule (see Appendix).

6) Elections take place. Voters vote sincerely based on their beliefs.

7) Media outlets update $c_{n, t}$ using Equation 6.

8) Losing party updates platform, following the decision-rule in Equation 1.

9) Voters update willingness to buy news $q_{v, t}$, following Equations 3 and 4 . Return to step 1.
}

\footnotetext{
${ }^{1}$ The model was programmed in $\mathrm{R}$ and - together with the data and scripts to reproduce the results in this paper - is made available on Harvard's Dataverse.

${ }^{2}$ Even in this day and age of social media many voters learn about politics from mass media outlets. See for example: http://people-press.org/report/652/. A model that includes social media-for example by adding a network component-is left for future work.
} 


\section{Parties}

Parties are office-motivated and have an ideal point $I_{p} \sim U(0,1)$ on a 0 to 1 ideological scale. Initial party positions are distributed such that parties are located on both sides of the median voter. After each election, the losing party changes its ideology by sampling a set of voters and moving by increment $\delta$ in the direction of the median voter, $M V$, of that sample. Formally:

$$
I_{p, t+1}=\left\{\begin{array}{ccc}
I_{p, t}+\delta & \text { if } & I_{M V, t}>I_{p, t} \\
I_{p, t}-\delta & \text { if } & I_{M V, t}<I_{p, t}
\end{array}\right.
$$

Equation 1 represents this updating rule. The learning parameter $\delta$ is fixed at 0.005 and represents a party's responsiveness to loss. Winning parties do nothing.

The incumbent party delivers policy outcome $y_{t}$ which is a function of its ideal point and a random shock, such that $y_{t} \sim T N\left(I_{p, i n c}, 1,0,1\right)$. That is, the policy outcome is represented as a draw from a truncated normal distribution, with mean equal to incumbent ideology, standard deviation equal to 1 , minimum equal to 0 , and the maximum to 1 . Policy outcomes thus depend on incumbent ideology and exogenous factors (see e.g., Ferejohn 1986).

\section{Voters}

Voters also have ideal points on the ideological 0 to 1 scale, represented as $I_{v} \sim U(0,1)$. In each period $t$, voter $v$ receives utility:

$$
U_{v, t}=-\left|I_{v}-y_{t}\right|-\left(\left(1-\alpha_{v}\right) c_{n, t}+\alpha_{v}\left|I_{v}-I_{n}\right|\right)
$$

where $\left|I_{v}-y_{t}\right|$ represents the ideological distance between the ideal point of voter $v$ and policy outcome $y_{t}$. Furthermore, $\left(\left(1-\alpha_{v}\right) c_{n, t}+\alpha_{v}\left|I_{v}-I_{n}\right|\right)$ represents the cost of news consumption, with $c_{n, t}$ the cost newspaper outlet $n$ charges for its reporting at time $t$ (more on this below), and $I_{n}$ the ideological location of media outlet $n$. Voter utility is thus a function of both policy outcomes and cost of news consumption. In addition, $\alpha_{v}$ is a voter-specific parameter that is distributed $\alpha_{v} \sim U(0,1)$. If $\alpha_{v}=0$, a (news-consuming) voter cares only about the cost of the news. If $\alpha_{v}=1$, 
a (news-consuming) voter cares only about is the ideological distance between herself and a media outlet; the larger this distance, the higher the cost of news consumption. Voters with $1>\alpha>0$ care both about news content and ideology. Thus, voters with $\alpha=0$ are only interested in content whereas voters with $\alpha=1$ are motivated reasoners who prefer-regardless of content-news reports from ideologically close news outlets to reports from ideologically distant outlets. ${ }^{3}$

All voters have incomplete information on party ideology $I_{p}$ since they observe policy outcome $y_{t}$, not ideology. Because of this incomplete information, voters hold beliefs over $I_{p}$, which are represented by a normal probability distribution, $\pi\left(I_{p}\right) \sim N\left(\mu, \sigma_{0}^{2}\right)$. Voters may decide to learn about both parties by buying news from the media. Thus, in each time period there are two groups of voters: news-buying voters and news-ignoring voters. Both groups of voters update their beliefs about the incumbent in response to information: news-ignoring voters learn from incumbent performance whereas news-buying voters directly learn incumbent ideology through media content. News-buying voters also learn in the news about challenger ideology, whereas news-ignoring voters do not since the challenger has not implemented policy in this round. Voters update their beliefs using Bayes' rule (Gerber and Green 1999). ${ }^{4}$

A voter's decision to purchase news occurs through a form of reinforcement learning. That is, voters increase (decrease) their likelihood of buying news if doing so has benefited (cost) them in the past (see also De Marchi 1999). Voters initially have an idiosyncratic interest in buying news from the media, denoted as probability $q_{v} \sim U(0,1)$, which is updated in each time period $t$. Furthermore, for each voter the decision to buy news in round $t$ is the outcome of a Bernouilli trial with probability $q_{v, t}$. Updating of $q_{v, t}$ occurs using the adaptive rules below (Fowler 2006; Bendor, Diermeier and Ting 2003). For voters who bought news in round $t$, the probability of buying news in round $t+1$ equals:

$$
q_{v, t+1}=\left\{\begin{array}{clc}
\min \left(1, q_{v, t}+\kappa\right) & \text { if } \quad U_{v, t}>U_{v, t-1} \\
\max \left(0, q_{v, t}-\kappa\right) & \text { if } \quad U_{v, t} \leq U_{v, t-1}
\end{array}\right.
$$

For voters who did not buy news in period $t$, the probability of buying news in round $t+1$

\footnotetext{
${ }^{3}$ For seminal work introducing motivated reasoning in political science see Taber and Lodge (2006)

${ }^{4}$ See the Appendix for details.
} 
equals:

$$
q_{v, t+1}=\left\{\begin{array}{ccc}
\max \left(0, q_{v, t}-\kappa\right) & \text { if } \quad U_{v, t}>U_{v, t-1} \\
\min \left(1, q_{v, t}+\kappa\right) & \text { if } \quad U_{v, t} \leq U_{v, t-1}
\end{array}\right.
$$

Voters thus compare current utility to utility in the previous period, which serves as the reference point from which they decide on what to do next (Bendor, Diermeier and Ting 2003). Voters who did not buy news in $t$ and who received more (less) utility in $t$ than in round $t-1$ decrease (increase) their likelihood of buying a newspaper in $t+1$, and vice versa for voters who did buy news in $t$. The learning parameter $\kappa$ is fixed at 0.005. It reflects voters' responsiveness to new information. In each round, voters choose a media outlet probabilistically, depending on the ideological distance between the outlet and the voter. ${ }^{5}$

\section{Media Outlets}

There are $N$ media outlets. Media outlets have fixed ideological ideal points $I_{n}$. Media outlets are motivated by audience share and the quality of the news. In each period $t$, media outlet $n$ receives utility:

$$
U_{n, t}=m_{n, t}-c_{n, t}
$$

where $m_{n, t}$ is the audience share of outlet $n$ at time $t$ and $c_{n, t}$ the cost / quality of its reporting. Since their ideological ideal points are fixed, all that media outlet $n$ can do to catch a larger share of the audience is to vary $c_{n, t}$. Media outlet $n$ tries to tailor to its readership by moving the quality of its reporting to the average taste for quality of a sample of their readers $q_{v, n, t}$, with the restriction that $U_{n, t} \geq 0$. This implies that the cost from increasing the quality of reporting cannot exceed the benefit from its readership. Thus, outlets with small readership experience a downward pressure on the quality of their coverage. Implicit in this assumption is that high quality (say, investigative)

\footnotetext{
${ }^{5}$ The probability of choosing each outlet is standardized using the total distance of all outlets. As a numerical example, let's say there are 5 news outlets located at distances $0.3,0.4,0.5,0.6$ and 0.7 from voter $V$. The probability that $V$ chooses the first outlet is $(1-0.3) /(0.3+0.4+0.5+0.6+0.7)=0,28$. The probability that $V$ chooses the fifth (and ideologically most distant) outlet is $(1-0.7) /(0.3+0.4+0.5+0.6+0.7)=0.12$.
} 
reporting is costly to make and less likely to occur if audience size is small, even if that audience prefers high quality reporting. Large media outlets on the other hand have more room to choose between low quality and high quality reporting.

To summarize, if quality of reporting is higher (lower) than the average preference for quality in a sample of readers, then a media outlet will decrease (increase) its quality by learning parameter $\mu=0.005$. Formally:

$$
c_{n, t+1}=\left\{\begin{array}{ccc}
\min \left(m_{n, t}-c_{n, t}, c_{n, t}+\mu\right) & \text { if } \quad c_{n, t}<\operatorname{mean}\left(q_{v, t}\right) \\
c_{n, t}-\mu & \text { if } \quad c_{n, t}>\operatorname{mean}\left(q_{v, t}\right)
\end{array}\right.
$$

\section{Analyzing the Model}

\section{Model Input}

To investigate how media competition and voter knowledge relate, I conduct Monte Carlo simulations randomly varying the competitiveness of the media system between 0 (no media), 1 (monopoly), 5 (medium competition) and 10 (high competition). In total I run 800 simulations, totaling 200 simulations of each level of media competition. Each simulation consists of 2000 time periods (see Table 1). Table 2 contains the starting values and distributions of all parameters for a single Monte Carlo run, and diagnostics are reported in the Appendix.

\section{Model Output}

The main dependent variable, voter knowledge, is measured as the averaged distance between voter beliefs and actual party ideology, across all $V$ voters and $P$ parties in the last 500 time periods. In what follows I recode this variable so that 1 denotes perfect knowledge and 0 no knowledge. Total audience share is measured as the average proportion of news-buying voters during the last 500 time periods, and average quality of reporting as the average quality of media coverage across outlets during the last 500 time periods. Furthermore, I calculate a Herfindahl Index score to measure media market competitiveness (Hirschman 1964) with 0 denoting perfect competition and 1 a monopoly. 
Table 2: Parameter Settings for Monte Carlo Simulation

\begin{tabular}{|c|c|c|}
\hline Parameter & Description & Default Value \\
\hline \multicolumn{3}{|c|}{ Random Parameters } \\
\hline $\mathrm{y}$ & Policy Shock & $\sim T N\left(I_{i n c}, 1,0,1\right)$ \\
\hline$I_{p}$ & Party Ideology & $\sim U(0,1)$ \\
\hline$I_{v}$ & Voter Ideology & $\sim U(0,1)$ \\
\hline$I_{n}$ & Media Outlet Ideology & $\sim U(0,1)$ \\
\hline$c_{n}$ & Initial Quality of Reporting & $\sim U(0,1)$ \\
\hline$q_{v}$ & Pr(Voter Purchases News) & $\sim U(0,1)$ \\
\hline \multicolumn{3}{|c|}{ Fixed Parameters } \\
\hline $\mathrm{V}$ & Number of Voters & 1001 \\
\hline $\mathrm{P}$ & Number of Parties & 2 \\
\hline $\mathrm{T}$ & Number of Time Periods & 2000 \\
\hline $\mathrm{R}$ & Number of Monte Carlo Runs & 800 \\
\hline$\delta$ & Party Learning Parameter & .005 \\
\hline$\kappa$ & Voter Learning Parameter & .005 \\
\hline$\mu$ & Media Learning Parameter & .005 \\
\hline
\end{tabular}

\section{Results}

I have not specified any hypotheses regarding the model results. Rather, I am treating the model as a tool to generate (exploratory) hypotheses, which in future work could be tested with (comparative) data.

\section{Competition}

Before turning to voter knowledge, I first note that the average herfindahl scores for monopoly media systems $(N=1)$, medium level competition $(N=5)$ and high level competition $(N=10)$ are 1, 0.22 and 0.12 respectively. Thus, with a larger supply of media outlets, news-reading voters tend to divide themselves amongst these outlets rather than converge on one particular outlet. Increasing the number of outlets thus increases competitiveness, 
Figure 1: Number of Media Outlets and Aggregate Voter Knowledge

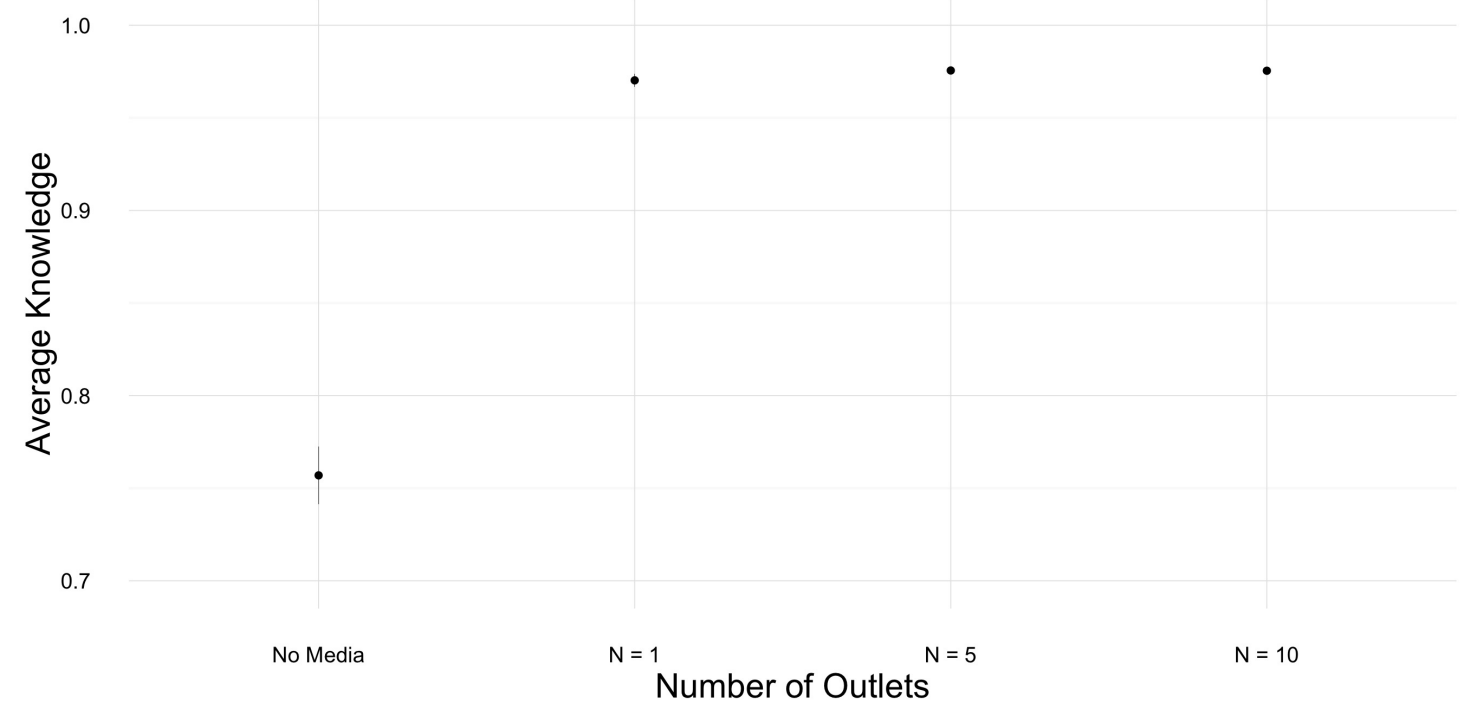

Note: The dots represent average knowledge level of the electorate in monopoly, medium competition and high competition media systems. The lines represent two standard errors above and below the estimated means. Aggregate political knowledge does not vary with the degree of media competition. In all three types of media systems voters well capable of locating their representatives.

\section{Knowledge}

Does competitiveness of a media system affect aggregate voter knowledge? The answer to this question is reported in Figure 1. It shows that at medium and high levels of media competition aggregate knowledge is similar to monopoly media systems: across all types of media systems voters on average are capable of locating the parties (0.98 under high and medium media competition versus 0.97 under media monopoly). ${ }^{6}$ This contrasts with a situation of no media presence (where voters can only learn from policy outcomes) where aggregate knowledge is only 0.76 . Thus if least one media outlet is present aggregated voter knowledge is high but it is hardly influenced by the degree of media competition.

Figures 2 and B.1 in the Appendix explain this pattern. First, Figure 2 shows that total audience share does not change with different levels of media competition. In addition, Figure B.1 shows that total audience share decreases rather quickly as time progresses in the model, which hurts the

\footnotetext{
${ }^{6}$ I have conducted additional Monte Carlo analyses with media systems of 2 and 3 outlets respectively. Under these media systems, aggregate knowledge is again at around 0.97.
} 
ability of outlets to produce high quality content since it is constrained by readership. In general, then, consumption of media content is low. Therefore, media competition has only little influence on aggregate political knowledge mostly because voters are paying only little attention to media outlets regardless of level of media competition.

Figure 2: Number of Media Outlets and Total Readership

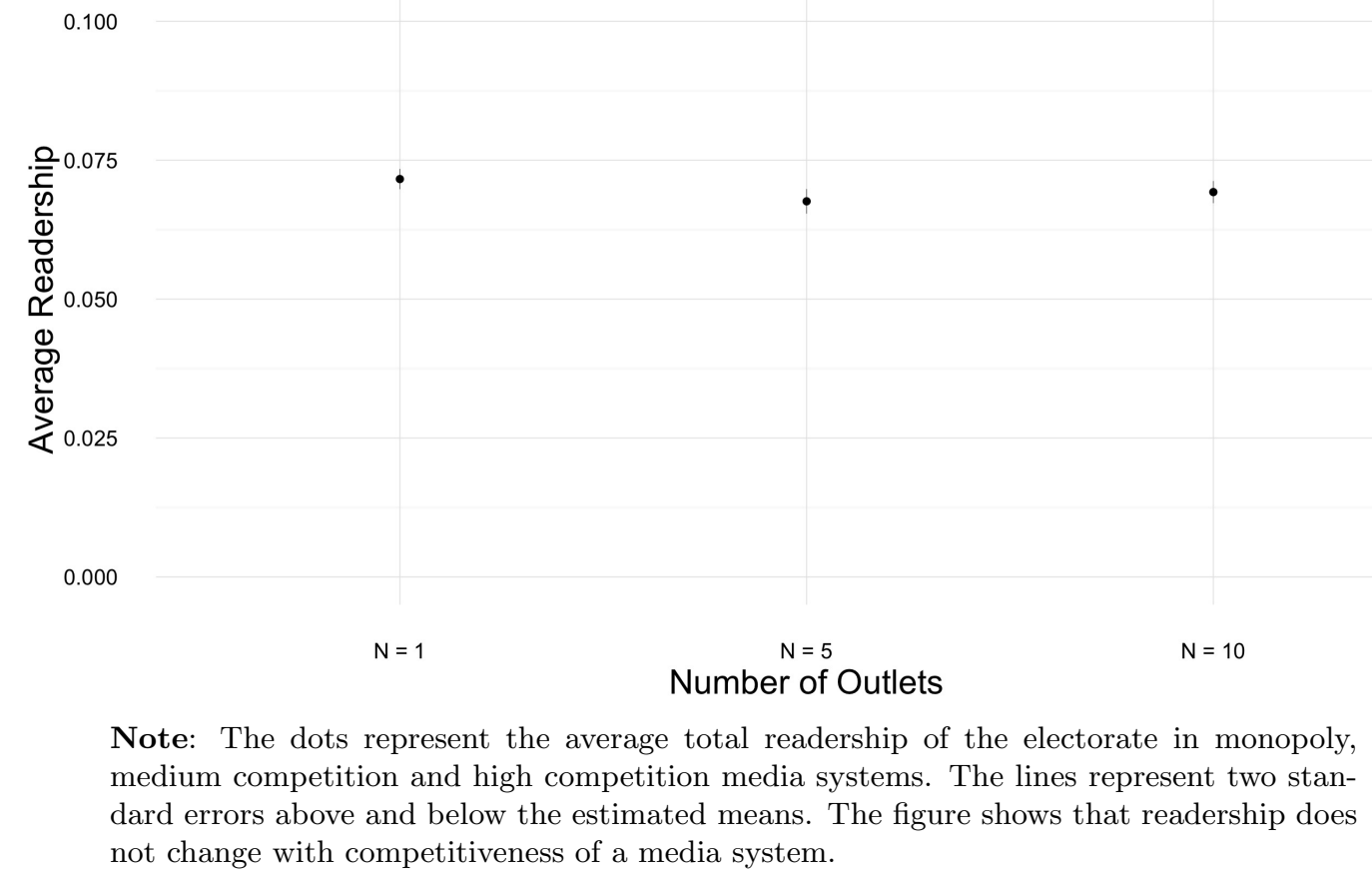

These aggregate patterns obscure relevant individual-level variation. Voters in the model care to different degrees about quality of the news vis-à-vis outlet ideology (characterized by parameter $\alpha$ ). Figure 3 displays how these preferences interact with media competition to affect political knowledge with each dot representing an individual voter's knowledge on the y-axis and $\alpha$ score on the $\mathrm{x}$-axis. The two (overlapping) black lines represent aggregate voter knowledge at different levels of $\alpha$ in medium and high competition media systems, and the red line represents aggregate knowledge at different levels of $\alpha$ in a monopoly media system. Although absolute differences are small, an interactive pattern emerges in which voters who care about news quality $(\alpha=0)$ are best-informed in systems of medium and high competition, in contrast to their counterparts in monopoly media systems. Yet these differences disappear for voters who care about ideology of 
Figure 3: Number of Media Outlets, Voter Preferences for News and Voter Knowledge

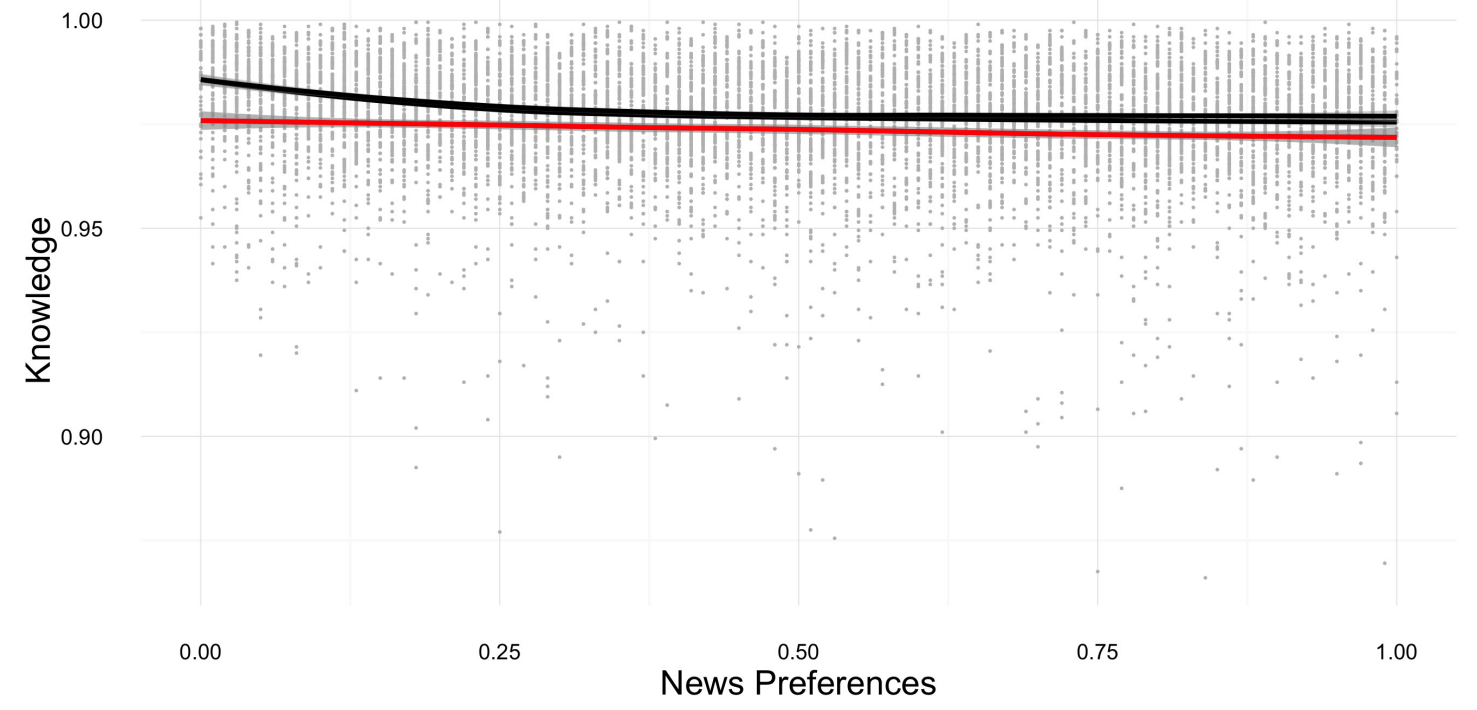

Note: The dots represent average knowledge of individual voters who vary in their levels of $\alpha$ ranging from 0 (voter cares only about quality of the news) to 1 (voter cares only about ideology of the media outlet), in monopoly, medium competition and high competition media systems. The two black lines represent aggregate knowledge at different levels of $\alpha$ in medium and high competition media systems, and the red line represents aggregate knowledge at different levels of $\alpha$ in a monopoly media system. The figure shows that voters who care about quality of the news tend to be best informed when media competition is medium or high, in contrast to their counterparts in a monopoly media system. These differences disappear for voters who care about the ideology of the media outlet.

media coverage $(\alpha=1)$ : these voters are about equally well-informed about the parties under all levels of media competition. In other words, it is voters who care about quality of the news who have the highest knowledge, but only if they find themselves in a media system of medium or high competition.

The reason for this is displayed in Figure 4, which plots the logarithm of the number of times a voter buys a newspaper against their preferences for news (with each dot representing an individual voter), aggregated across systems of high and medium competition (black lines), and a monopoly media system (red line). The figure shows an interactive pattern in which voters who care about news quality news attend to coverage more often when media competition is at high or medium level. In contrast, voters who only care about the ideology of their newspaper of choice are least likely to buy a newspaper when media competition is medium or high.

Thus, voters who care about quality of the news tend to be best-informed about party ideology 
Figure 4: Number of Media Outlets, Voter Preferences for News and Audience Share

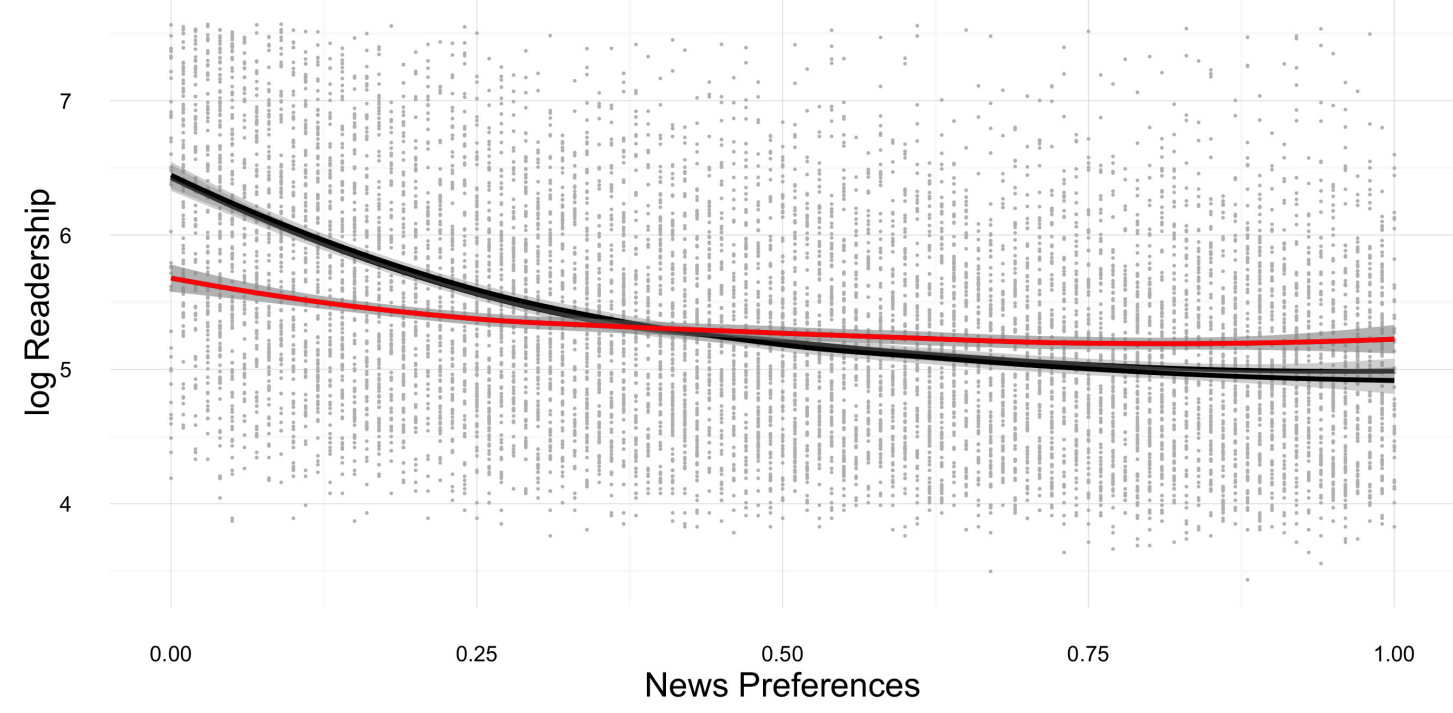

Note: The dots represent the logarithm of the number of times individual voters-who vary in their levels of $\alpha$ ranging from 0 (voter cares only about quality of the news) to 1 (voter cares only about ideology of the media outlet) - buy a newspaper, in monopoly, medium competition and high competition media systems. The two black lines represent aggregate audience share at different levels of $\alpha$ in medium and high competition media systems, and the red line represents aggregate audience share at different levels of $\alpha$ in a monopoly media system. The figure shows an interactive pattern in which voters who care about quality of the news most often buy a newspaper when media competition is at high or medium level, compared to their counterparts in a monopoly media system. Voters who only care about the ideology of their newspaper of choice are least likely to buy a newspaper when media competition is medium or high.

since they are most likely to consume news, despite low quality of coverage because of low audience

share. However, these same voters in a monopoly media system would be less likely to buy news and more likely to resemble - with regards to political knowledge and willingness to buy a newspapervoters who only care about the ideology of media. Thus, media competition benefits different groups of voters differentially, even though aggregate patterns of voter knowledge are similar.

\section{Conclusion}

The ABM presented here shows that variation in voter knowledge is in part be driven by competition among media outlets. The model predicts that increased competition among media outlets enhances political knowledge of news-reading, quality-minded voters, but that aggregate differences do not 
depend on the degree of media competition (but do depend on the presence of media outlets in the first place).

Of course, the model has both strengths and weaknesses. To begin with the latter, the behavioral assumptions make this model abstract. For example, voters have no stable individual characteristics but their ideology and their quality preferences. In reality, of course, behavioral research has shown that individual characteristics beyond those modeled here explain political behavior and attitudes. Furthermore, the model locates electoral competition on a one-dimensional ideological space where a two- or multi-dimensional issue space may empirically be more realistic. Also, the behavioral decision rules specified for each type of actor in the model are intuitive but other, similarly plausible decision rules exist (e.g., imitation).

That being said, the model also makes theoretical and empirical contribution. Theoretically, it can serve as a starting point for the types of adjustments I just mentioned. After all, behavioral decision rules can be easily adjusted in future work. Empirically, the model helps our understanding of voter knowledge in the context of increased media competition. As such, it contributes to a new neo-institutional approach in political science that models voter knowledge as a function of not just individual characteristics but of institutional factors as well (e.g., Gordon and Segura 1997). This contextual approach is exciting and intuitive but it runs the risk of false positives and false negatives. After all, because of their mutual interdependence, the causal mechanisms underlying voter knowledge, mass media reports and electoral competition are hard to disentangle with empirical data alone (see for example (Curran et al. 2009; Prat and Strömberg 2005). We thus need further theory development and the model presented in this paper has contributed to that goal.

\section{References}

Baum, M.A. and P.B.K. Potter. 2008. "The Relationships Between Mass Media, Public Opinion, and Foreign Policy: Toward a Theoretical Synthesis." Annual Review of Political Science 11(1):39-65. 
Bendor, Jonathan, Daniel Diermeier and Michael Ting. 2003. "A Behavioral Model of Turnout." American Political Science Review 97(02):261-280.

Curran, J., S. Iyengar, A.B. Lund and I. Salovaara-Moring. 2009. "Media System, Public Knowledge and Democracy: A Comparative Study." European Journal of Communication 24(1):5-26.

De Marchi, S. 1999. "Adaptive models and Electoral Instability." Journal of Theoretical Politics 11(3):393-419.

Ferejohn, J. 1986. "Incumbent Performance and Electoral Control." Public choice 50(1):5-25.

Fowler, J.H. 2006. "Habitual voting and behavioral turnout." Journal of Politics 68(2):335-344.

Gentzkow, M. and J.M. Shapiro. 2008a. Market Forces and News Media in Muslim Countries. In Information and Public Choice: From Media Markets to Policy Making, ed. R. Islam. World Bank Publications.

Gentzkow, Matthew and Jesse M Shapiro. 2008b. "Competition and Truth in the Market for News." The Journal of Economic Perspectives 22(2):133-154.

Gerber, A. and D. Green. 1999. "Misperceptions About Perceptual Bias." Annual Review of Political Science 2(1):189-210.

Gordon, Stacy B and Gary M Segura. 1997. "Cross-National Variation in the Political Sophistication of Individuals: Capability or Choice?" Journal of Politics 59(1):126-147.

Hallin, D.C. and P. Mancini. 2004. Comparing Media Systems: Three Models of Media and Politics. Cambridge University Press.

Hirschman, A.O. 1964. "The Paternity of an Index." The American Economic Review 54(5):761762.

Hopkins, Daniel J, Eunji Kim and Soojong Kim. 2017. "Does Newspaper Coverage Influence or Reflect Public Perceptions of the Economy?" Research \& Politics 4(4). 
Jerit, J., J. Barabas and T. Bolsen. 2006. "Citizens, Knowledge, and the Information Environment." American Journal of Political Science 50(2):266-282.

Kollman, K, J.H Miller and S.E Page. 1992. "Adaptive Parties in Spatial Elections." American Political Science Review 86(4):929-937.

Kollman, K, J.H Miller and S.E Page. 1998. "Political Parties and Electoral Landscapes." British Journal of Political Science 28(1):139-158.

Laver, M. 2005. "Policy and The Dynamics of Political Competition." American Political Science Review 99(02):263-281.

Laver, M. and E. Sergenti. 2011. Party Competition: An Agent-Based Model. Princeton University Press.

Laver, M. and M. Schilperoord. 2007. "Spatial Models of Political Competition With Endogenous Political Parties." Philosophical Transactions of the Royal Society B: Biological Sciences 362:1711-1721.

Prat, A. and D. Strömberg. 2005. "Commercial Television and Voter Information." CEPR Discussion Paper.

Schoonvelde, Martijn. 2014. "Media Freedom and the Institutional Underpinnings of Political Knowledge." Political Science Research and Methods 2(02):163-178.

Snyder Jr, J.M. and D. Strömberg. 2010. "Press Coverage and Political Accountability." Journal of Political Economy 118(2):355-408.

Strömbäck, Jesper. 2008. "Four Phases of Mediatization: An Analysis of the Mediatization of Politics." The International Journal of Press/Politics 13(3):228-246.

Taber, C.S. and M. Lodge. 2006. "Motivated Skepticism in the Evaluation of Political Beliefs." American Journal of Political Science 50(3):755-769. 


\section{A Bayesian updating of voter beliefs}

Belief updating or learning takes place as follows. News-ignoring voters update their beliefs in response to policy performance, which is represented as a draw from a normal distribution $N\left(y_{t}, \sigma_{1}^{2}\right)$ with mean equal to the policy outcome $y_{t}$ and variance equal to 2 . The variance is equal to 2 because policy is the sum of two standard normal variables that are independent and identically distributed (i.i.d.). News-buying voters on the other hand learn about ideology directly from media content, which is represented by a normal distribution $N\left(I_{p, t}, \sigma_{1}^{2}\right)$ with mean equal to party ideology and variance equal to the inverse of the quality of the news. The variance of the signal varies between zero and one. Thus, the higher the quality of the news, the more informative it is to the news-buying voter.

Assuming that news (either policy outcomes or media reports) is represented by a draw $x \sim$ $N\left(\mu_{1}, \sigma_{1}^{2}\right)$, Bayes' rule implies that voters' posterior beliefs $\pi\left(I_{p} \mid x\right) \sim N(\mu(x), \rho)$, where

$$
\begin{gathered}
\mu(x)=\mu+(x-\mu) \frac{\sigma_{0}^{2}}{\sigma_{0}^{2}+\sigma_{1}^{2}} \\
\rho=\frac{\sigma_{0}^{2} \sigma_{1}^{2}}{\sigma_{0}^{2}+\sigma_{1}^{2}}
\end{gathered}
$$

That is, voters beliefs after observing 'news' have mean $\mu(x)$, which is a function of their prior belief $\mu$ and the news $x$. The strength of that belief is represented by $\rho$. The smaller $\rho$, the stronger the belief is. Both $\mu(x)$ and $\rho$ also depend on $\sigma_{0}^{2}$ and $\sigma_{1}^{2}$ which denote the variance of the prior belief and the variance of the news respectively. 


\section{B Diagnostics}

Output variables from ABMs are most informative when generated from steady state processes (and not from a system that is still in flux). To evaluate when key output variables of the model reach steady state I first run the model for an increasing number of time periods, starting from 250 . Graphing the results, it appears that voter knowledge, average quality of reporting, and the total audience share all have converged after around 1500 time periods, as displayed in the figure below. In contrast, herfindahl seems not to converge as time progresses but instead its variance seems to increase somewhat. A primary reason for this is that as the model evolves the total audience share goes down to under $10 \%$ of voters. Since the herfindahl index only takes into account the relative size of each newspaper's readership - and not its absolute size - minor changes among this small group of readers will have a relatively large influence on the value of the herfindahl index.

With these results in mind, in the analysis I discard the first 1500 time periods of each simulation (treating them as 'burn-in') and collect output variables on the last 500 observations. In addition, by aggregating outcomes across these last 500 time periods, I am purging the results from random measurement error, like in the case of the herfindahl scores. The results of the outcome variables are not be interpreted in terms of long-run time series but instead as 'evolved' outcomes for a particular level of media competition. 
Figure B.1: Convergence of Outcome Variables in a Single Run of the Model
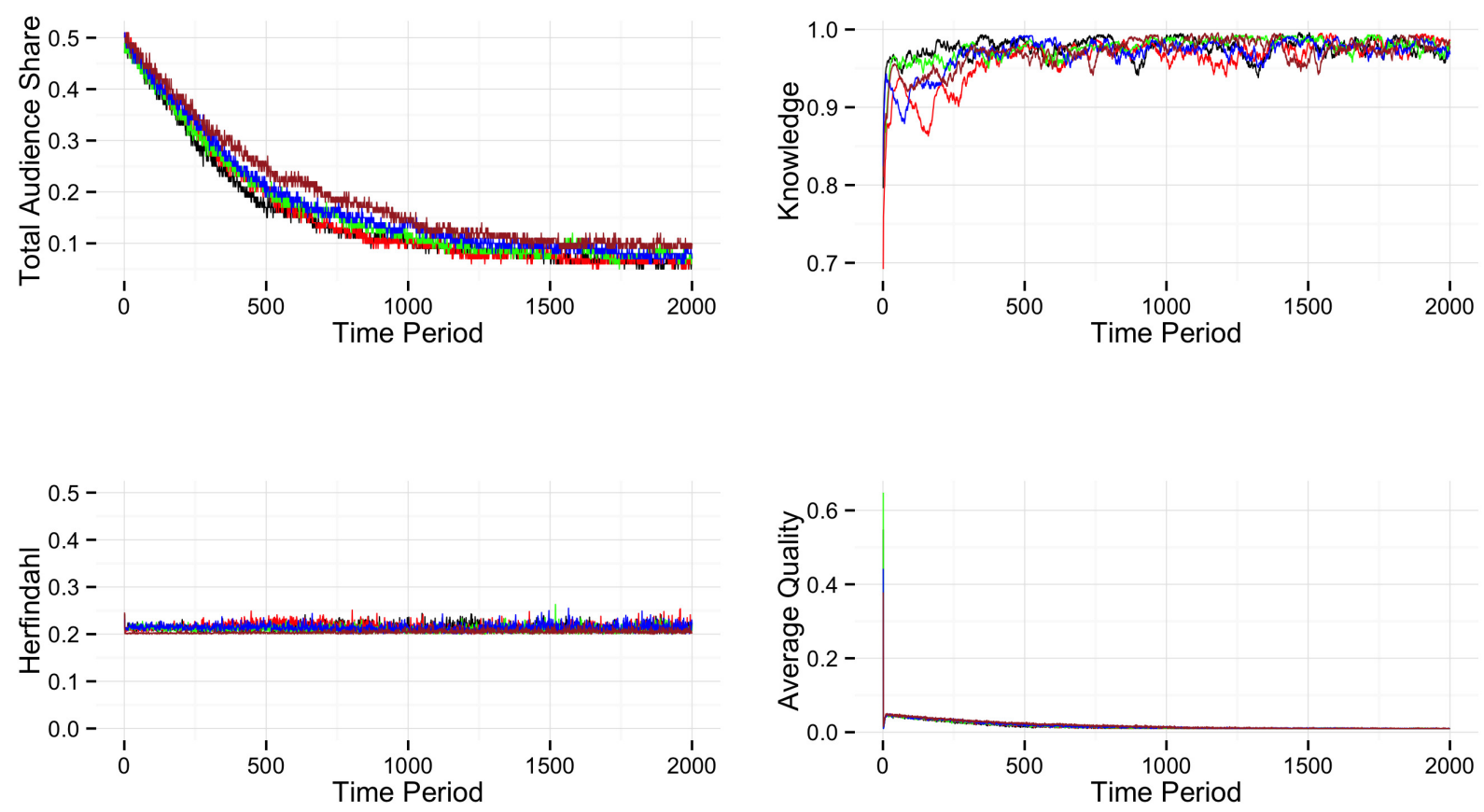

Note: This figure displays total audience share, voter knowledge, average quality, and herfindahl in each time period across five runs of the model with 5 media outlets. The figure shows that the first four of these variables have all converged after about 1500 time periods. The variation in the Herfindahl on the other hand seems to slightly increase as time progresses, mainly because the total audience share decreases to a small proportion of the overall electorate and with the index scores very sensitive to small changes in audience share. 